\title{
INTERACTION OF CENTRAL NERVOUS SYSTEM DRUGS WITH SYNAPTOSOMAL TRANSPORT PROCESSES
}

\author{
Anne L. Cahill and Fedor Medzihradsky* \\ Departments of Biological Chemistry and Pharmacology, and Upjohn Center for Clinical Pharmacology, \\ The University of Michigan Medical Center, Ann Arbor, Mich. 48109, U.S.A.
}

(Received 12 November 1975; accepted 5 March 1976)

\begin{abstract}
Interaction of a wide range of central nervous system (CNS) drugs with the transport of 5-hydroxytryptamine (5-HT) and norepinephrine (NE) into synaptosomes from cerebral cortex was investigated. By determining the effect on Na.K-ATPase, the interaction of these drugs with the synaptic transport of $\mathrm{Na}^{+}$and $\mathrm{K}^{+}$was also assessed. Although of different numerical value, the order of potency of the drugs in inhibiting the uptakes of both biogenic amines was comparable. Furthermore, similar inhibition constants were obtained for the low affinity uptake of 5-HT and the uptake of NE. Desipramine and amphetamine strongly inhibited both uptake processes. The narcotic drugs displayed a wide range of inhibitory potency. $\Lambda \mathrm{n}$ exceptionally strong, but not stereospecific, effect was obtained with levorphanol, which inhibited 5-HT uptake with a $K_{i}$ of $0.7 \mu \mathrm{M}$. While methadone and pentazocine had inhibition constants between 20 and $50 \mu \mathrm{M}$, morphine, codeine and naloxone were markedly weak inhibitors with $K_{1}$ values extending into the $\mathrm{mM}$ range. The uptake of both 5-HT and NE was strongly inhibited by quinacrine. Among the drugs investigated, only methadone showed substantial inhibition of synaptosomal Na,K-ATPase. The reversible inhibition of the enzyme by the drug was diminished at concentrations of $\mathrm{Na}^{+}$and $\mathrm{K}^{+}$reflecting synaptic discharge. The drug partially bound to the ouabain site of $\mathrm{Na}, \mathrm{K}-\mathrm{ATPase}$ and also inhibited the $\mathrm{Mg}$-activated component. The feasibility and experimental conditions were established for using a modified crude mitochondrial fraction as synaptosomal preparation to study transport processes in general and the uptake of biogenic amines in particular.
\end{abstract}

Various central nervous system (CNS) drugs may owe their pharmacologic action to an interaction with the synaptic uptake of biogenic amines $[1,2]$. Accordingly, a number of studies were conducted on the inhibition by selected CNS drugs of the uptake of 5-hydroxytryptamine (5-HT) [3-6], as well as dopamine (DA) and norepinephrine (NE) [7-11]. However, a comparison and unequivocal interpretation of the results of these experiments are hampered hy the manifold approaches in investigating and presenting the inhibitory potencies of the drugs, as well as by the limited sclection of compounds included in a given study. An additional difficulty in evaluating the hitherto presented information is created by the different sources of synaptosomes, ranging from whole brain to several discrete areas of the cerebrum.

In addition to the uptake of biogenic amines, the transport of $\mathrm{Na}^{+}$and $\mathrm{K}^{+}$across the presynaptic membrane represents another major process of translocation in the synaptic cleft. The molecular mechanism for the active transport of monovalent ions involves the $\mathrm{Na}, \mathrm{K}-\mathrm{ATPase}$. This enzyme is associated with cell membranes and is particularly active in excitable tissues [12]. Its presence was described and its activity characterized in synaptosomes [13]. The effects of a limited selection of CNS drugs, particularly tricyclic antidepressants, on synaptosomal Na,K-ATPase were previously investigated [14,15]

Although reports on uptake processes in synaptosomes are manifold, there is a lack of information

* Send requests for reprints to: Dr. Fedor Medzihradsky, Department of Biological Chemistry, The University of Michigan Medical School, Ann Arbor, Mich. 48109. on criteria which have to be fulfilled by isolated synaptosomal preparations in order to render them suitable for the study of transport processes.

Against this background, and within our interest in mechanisms of cellular drug transport [16-19], it was decided to investigate the interaction of a wide selection of CNS drugs with the uptake of biogenic amines in synaptosomes isolated from one discrete area of the brain, the cerebral cortex. Another goal of this study was to determine the effects of the drugs on the synaptosomal Na,K-ATPase at concentrations of the two ions which reflect both normal and discharge states in the synaptic cleft. Finally, the study was to re-evaluate experimental conditions for investigating transport processes in synaptosomal preparations.

\section{MATERIALS AND MEIHODS}

Materials. The drugs used in this study were kindly provided by Drs. H. H. Swain and J. H. Woods, Department of Pharmacology, The University of Michigan Medical School. Tritium-labeled (G) 5-HT, $\mathrm{DA}$ and NE as well as Protosol were obtained from Amersham/Searle Corp., Arlington Heights, Ill., Mallinckrodt Chemical Works, St. Louis, Mo, and New England Nuclear Corp., Boston, Mass. respectively. Ficoll and bovine serum albumin (BSA), as well as the biochemicals used in the assay of acetylcholinesterase $(\mathrm{AChE})$, succinate dehydrogenase $(\mathrm{SDH})$, lactate dehydrogenase (LDH) and $\mathrm{Na}, \mathrm{K}-\mathrm{ATP}$ ase, were purchased from Sigma Co., St. Louis, Mo.. or Boehringer-Mannheim Corp., New York, N.Y. All other chemicals were of reagent grade.

Isolation of synaptosomal preparations. The synaptosomal preparation was isolated from cortices of 
male Spraguc-Dawlcy rats wcighing $180 \mathrm{~g}$. The procedure adapted was a modification of the method of Autilio et al. [20]. The preparation of tissue was carried out at 4 . The cerebral cortices were dissected free of white matter and homogenized in $0.32 \mathrm{M} \mathrm{su}$ crose at a concentration of $10 \%(\mathrm{w} / \mathrm{v})$. The disruption of tissue was carried out at $500 \mathrm{rev} / \mathrm{min}$ in a PotterElvehjem homogenizer equipped with a Teflon pestle. After centrifugation at $1000 \mathrm{~g}$ for $10 \mathrm{~min}$, the pellet containing nuclei and cell debris was discarded and the supernatant centrifuged at $15,000 \mathrm{~g}$ for $20 \mathrm{~min}$ The resulting pellet, representing the crude mitochondrial fraction $(\mathrm{CM})$, consisted of a relatively loose, light-colored layer on top of a firm yellow portion at the bottom of the centrifuge tube. The upper part of the pellet was carefully resuspended and decanted, leaving the bottom layer undisturbed. The suspension of the latter was referred to as modified crude mitochondrial fraction (MCM) and was predominately used in this study as the synaptosomal preparation.

In separate experiments, purified synaptosomes were obtained by fractionating the initial tissue homogenate using density gradient centrifugation according to Autilio et al. [20] or Gray and Whittaker [21].

Isolation of mitochondria. In a number of experiments, mitochondria from cerebral cortices of rats were isolated according to several procedures reported to result in little contamination by other organelles, particularly synaptosomes [22-25].

Characterization of MCM fraction. The activity of AChE was determined according to the method of Ellman et al. [26]. The procedure is based on the cleavage of acetylthiocholine iodide and the determination of absorbance at $413 \mathrm{~nm}$ of the formed anion, 5-thio-2-nitrobenzoic acid. The reaction was started by the addition of an aliquot of the MCM fraction suspended in $0.32 \mathrm{M}$ sucrose and corresponding to 0.02 to $0.10 \mathrm{mg}$ protein.

The determination of SDH activity was carried out by the method of King [27], which utilizes the oxidation of succinate in the presence of 2.6-dichlorophenolindophenol and phenazine methosulfate. The reduction of indophenol is followed at $600 \mathrm{~nm}$. The reaction was initiated by the addition of an aliquot of the MCM fraction, corresponding to 0.02 to $0.10 \mathrm{mg}$ protein.

The activity of LDH was determined by measuring the initial rates of pyruvate reduction coupled to a decrease in fluorescence of reduced nicotinamide adenine dinucleotide (NADH). Final concentrations in the assay medium were: imidazol $\cdot \mathrm{HCl}(\mathrm{pH} 7.4)$, $20 \mathrm{mM}$ : pyruvate. $1 \mathrm{mM}$ : NADH, $0.01 \mathrm{mM}$; BSA $0.02^{\circ} \mathrm{o}$. For the determination of total LDH in the MCM fraction, an aliquot of the suspension in $0.32 \mathrm{M}$ sucrose was frozen four times at -70 and thawed, centrifuged at $35,000 \mathrm{~g}$ for $5 \mathrm{~min}$, and an aliquot of the supernatant used to measure enzyme activity. For estimation of $\mathrm{LDH}$ release during storage of the MCM fraction. an aliquot of the suspension in $0.32 \mathrm{M}$ sucrose was added to $2 \mathrm{ml}$ of the buffer medium used in the uptake experiments. After incubation for $15 \mathrm{~min}$ at $20^{\circ}$, the suspension was centrifuged at $35,000 \mathrm{~g}$ for $5 \mathrm{~min}$ and the $\mathbf{L D H}$ activity in the supernatant determined.

The cellular concentrations of $\mathrm{Na}^{+}$and $\mathrm{K}^{+}$were determined by flame photometry, with $\mathrm{LiCl}$ as inter- nal standard [28]. After various times of storage at 0 , aliquots of the MCM fraction in $0.32 \mathrm{M}$ sucrose corresponding to about $3 \mathrm{mg}$ protein were added to $2 \mathrm{ml}$ buffer medium. After incubation for $15 \mathrm{~min}$ at $20^{\circ}$, the suspension was centrifuged at $35,000 \mathrm{~g}$ for $5 \mathrm{~min}$. The pellet was washed three times by suspension in $0.32 \mathrm{M}$ sucrose and renewed centrifugation. The resulting pellet was digested at room temperature overnight with $50 \mu \mathrm{l}$ conc. $\mathrm{HNO}_{3}$. After the addition of $5 \mathrm{ml}$ of $15 \mathrm{mEq} / 1$. LiCl, the concentrations of $\mathrm{Na}^{+}$and $\mathrm{K}^{+}$were determined in a llame photometer.

Conditions for uptake studies. The MCM fraction was prepared as described above by suspending the upper, loose portion of the CM pellet in $3-4 \mathrm{ml}$ of $0.32 \mathrm{M}$ sucrose, $\mathrm{pH} 7.4$. The suspension was kept on ice and, as needed, $100 \mu \mathrm{l}$ of it was transferred to $2.15 \mathrm{ml}$ buffer medium, containing the drugs the effects of which were investigated. The buffer medium had previously been equilibrated with $\mathrm{O}_{2}$ at 20 and contained the following final concentrations $(\mathrm{mM})$ : Tris, 35: $\mathrm{NaCl}, 100 ; \mathrm{KCl}, 10 ; \mathrm{MgSO}_{4}, 1.2: \mathrm{KH}_{2} \mathrm{PO}_{4}$. 1.2; $\mathrm{NaHCO}_{3}, 1$; glucose, 10; and sucrose, 25. The $\mathrm{pH}$ of the medium was adjusted to 7.4 with $\mathrm{HCl}$. The determined tonicity of the buffer medium was $317 \mathrm{mOsM}$. After incubating the suspension for $5 \mathrm{~min}$ at $20,250 \mu \mathrm{l}$ of a solution of radiolabeled biogenic amine in the buffer medium was added and all the samples were incubated for a time between 2 and 5 min with gentle shaking under $\mathrm{O}_{2}$. The incubation was terminated by filtering $1-\mathrm{ml}$ aliquots on Reeve Angel ultrafine glass fiber disks which initially were repeatedly swirled in fresh portions of $0.9^{\circ}, \mathrm{NaCl}$. The material on the filter was washed with $25 \mathrm{ml}$ of ice-cold $0.9 \% \quad \mathrm{NaCl}$. Total filtration time was 20-30 sec. The filters were transferred to scintillation vials, digested with $0.4 \mathrm{ml}$ Protosol at 60 for $1 \mathrm{hr}$ and cooled to room temperature. Toluene-based scintillation fluid was then added and the radioactivity determined in a liquid scintillation spectrometer.

To estimate nonspecific interactions with biologic material, control experiments were carried out with synaptosomal preparations previously repeatedly frozen at -70 and thawed, or sonicated $3 \times 20 \mathrm{sec}$ at 0 using a microtip at setting 6 of a Branson cell disruptor, model W140.

Assay of $\mathrm{Na}, K$-ATPase. The activity of this enzyme was determined by measuring the catalyzed release of inorganic phosphate $(\mathrm{Pi})$ from ATP. The determination of Pi was carried out enzymatically utilizing phosphorylase $a$, phosphoglucomutase and glucose 6-phosphate dehydrogenase [29]. The assay of $\mathrm{Na}, \mathrm{K}$-ATPase was carried out as previously described [30] and its activity calculated from the difference in $\mathrm{Pi}$ release in the absence and presence of $0.1 \mathrm{mM}$ ouabain. The specific conditions of experiments on drug interaction with the enzyme are outlined in the legends

Determination of protein. Protein was determined by the method of Lowry et al. [31]

\section{RESLLTS}

Characterization of MCM fraction. The preparation was characterized, and the reproducibility of the isolation procedure investigated by determining the specific activity of $\mathrm{AChE}, \mathrm{SDH}$ and $\mathrm{LDH}$ sell 
content of $\mathrm{Na}^{+}$and $\mathrm{K}^{+}$, as well as the yield of protein. The obtained mean values, expressed per $\mathrm{mg}$ of protein, were: $100 \pm 2$ nmoles $/ \mathrm{min}$ (AChE), $18 \pm 2$ nmoles $/ \mathrm{min} \quad(\mathrm{SDH}), \quad 240 \pm 20 \mathrm{nmoles} / \mathrm{min}$ $(\mathrm{LDH}), 49 \pm 14 \mathrm{nEq}\left(\mathrm{Na}^{+}\right)$and $133 \pm 33 \mathrm{nEq}\left(\mathrm{K}^{+}\right)$. The yield of protein was $17.6 \pm 1.4 \mathrm{mg} / \mathrm{g}$ of cortical wet weight. Specific activity (in units as above) of $\mathrm{AChE}$ in $\mathrm{CM}$ preparations from whole rat brain was reported as 161 [32] and 68 [33], whereas in purified synaptosomes it was 216 [32], 100 [34], 56 [33] and 38 [35]. The activity of SDH in mitochondria and in isolated synaptosomes was 305 and 148 nmoles/mg of protein $\cdot \min$ respectively [35]. LDH activity ranged from $117 \mathrm{nmoles} / \mathrm{mg}$ of protein.min in $\mathrm{CM}$ from whole rat brain [32] to 90 [34] and 305 nmoles/mg of protein $\min [32]$ in isolated synaptosomes. The reported yield of protein, per $\mathrm{g}$ of tissue wet weight, was $61 \mathrm{mg}$ [33] and $83 \mathrm{mg}$ [32] in CM from whole rat brain, $23 \mathrm{mg}$ in $\mathrm{CM}$ from rat cerebral cortex [36] and $11 \mathrm{mg}$ [34],10 $\mathrm{mg}$ [36] and $12 \mathrm{mg}$ [33] in isolated synaptosomes.

The viability of the MCM fraction relating to study of transport processes, i.e. the presence of an intact plasma membrane [37], was ascertained by the unchanged cellular concentrations of $\mathrm{K}^{+}, \mathrm{Na}^{+}$and LDH (Fig. 1). Reported initial ratios of $\mathrm{K}^{+} / \mathrm{Na}^{+}$in isolated synaptosomes ranged from 0.35 [38] to 1.51 $[39\rceil$ and 4.75 [40].

Validity of utilizing the MCM fraction for investigating synaptosomal uptake processes. The possible contribution of mitochondria to data reflecting transport of biogenic amines in the MCM fraction was investigated using the following approach: (a) mitochondria were isolated by several procedures reported to result in little contamination by synaptosomes or other organelles; (b) the specific activity of $\mathrm{SDH}$, used as mitochondrial marker, was determined in the mito-
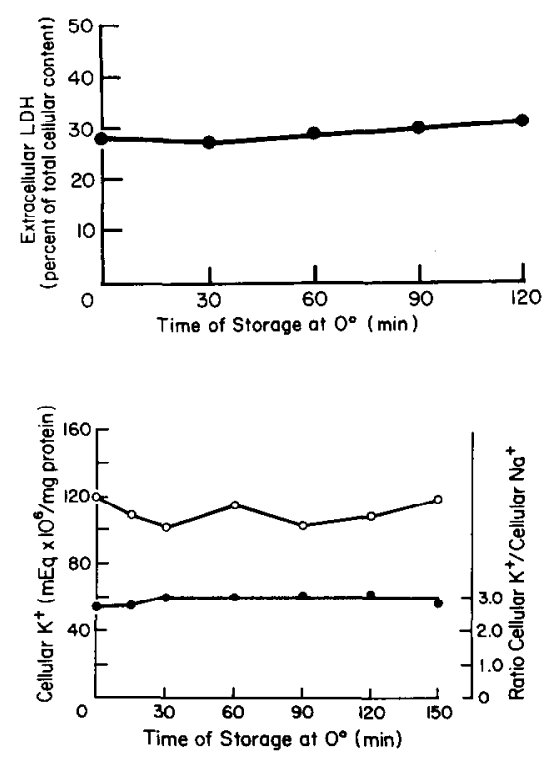

Fig. 1. Time dependence of cellular concentrations of $\mathrm{LDH}, \mathrm{K}^{+}$and $\mathrm{Na}^{+}$. After various times of storage at 0 in $0.32 \mathrm{M}$ sucrose, aliquots of the MCM fractions were added to the buffer medium and incubated for $15 \mathrm{~min}$ at 20. Subsequently, $\mathrm{LDH}, \mathrm{K}^{+}(\mathrm{O}-\mathrm{O})$ and $\mathrm{Na}^{+}$were determined as described in Materials and Methods. Results are averages of three experiments. chondrial fractions as well as in the MCM preparation; (c) total amount of protein was determined in the isolated mitochondria and expressed as per cent of the CM fraction from which they were separated; (d) the uptake of 5-HT in the various isolated mitochondrial preparations and in the MCM fraction was determined: and (e) considering the results of protein determination, the uptake of 5-HT in the MCM fraction was compared with that obtained using the isolated mitochondria.

The results of the above outlined experiments are shown in Table 1. From the obtained data, the magnitude of possible contribution of mitochondria to the uptake of 5-HT in the MCM preparation was determined to be about 5 per cent. In addition to these experiments, the $\mathrm{CM}$ fraction was incubated with radiolabeled 5-HT and the preparation subsequently resolved by density gradient centrifugation into enriched synaptosomal and mitochondrial fractions, according to Gray and Whittaker [21]. The radioactivity in the latter two fractions corresponded to 90 and 4 per cent of the total activity applied to the gradient. It should also be emphasized that in the MCM fraction used in this study the contamination by mitochondria was less than in the unmodified CM preparation. This was documented by the SDH specific activity in the MCM fraction relative to the lower portion of the CM pellet: 18 and $39 \mathrm{nmoles} / \mathrm{mg}$ of protein $\cdot \min$ respectively

Uptake of 5-HT and NE. The linear ranges of the uptake of biogenic amines are shown in Fig. 2, and the kinetics of the processes are presented in Figs. 3 and 4. In view of the biphasic nature of 5-HT uptake, the initially obtained "masked" values for both $K_{m}$ and $V_{\max }$ were re-evaluated (Table 2) according to the method of Neal [41]. The latter correction takes into consideration the mutual interaction of the two processes, representing the low and high affinity uptake of 5-HT.

The results on the uptake of DA were characterized by inconsistency, caused by low uptake rates. In view of the poor reproducibility of the uptake itself no attempts were made to investigate drug interaction with the latter process.

Interaction of drags with the uptake of 5-HT and $N E$. The nature of drug interaction was analyzed graphically and the inhibition constants were obtained from Dixon plots of the uptake of biogenic amines in the presence of the drugs (Fig. 5). The $K_{i}$ values are listed in Table 3 . There was a general similarity in the pattern by which the investigated drugs inhibited the uptake of 5-HT and NE. $K_{i}$ values relating to the low affinity uptake of 5-HT correlated well with inhibition constants of the drugs displayed in the uptake of NE. On the basis of their potency in inhibiting the uptakc of both 5-IIT and NE, all the investigated drugs could be divided into three distinct categories, characterized by $K_{i}$ values of: below $12 \mu \mathrm{M}$, between 20 and $50 \mu \mathrm{M}$, and above $300 \mu \mathrm{M}$ (Table 3). An exceptional effect was obtained with levorphanol, which inhibited 5-HT uptake with a $K_{i}$ in the submicromolar range. Both levorphanol and dextrorphan displayed similar $K_{i}$ values. Codeine, morphine and naloxone, on the other hand, affected both uptake processes least. Their interaction was characterized by high $K_{i}$ values, extending into the $\mathrm{mM}$ range particularly in inhibiting NE uptake. Both 
Table 1. Uptake of 5-HT in isolated mitochondria (M) and in MCM fraction*

\begin{tabular}{|c|c|c|c|c|}
\hline $\begin{array}{l}\text { Method for } \\
\text { isolation } \\
\text { of } \mathrm{M}\end{array}$ & $\left(\begin{array}{c}\text { SDH activity } \\
\text { nmoles } \\
\text { mg protein } \cdot \min \end{array}\right)$ & $\begin{array}{c}\text { M protein } \\
\text { (per cent of total } \\
\text { MCM protein) }\end{array}$ & $\begin{array}{l}\text { Uptake of } 5-\mathrm{HT} \\
\text { in fractiont } \\
\left(\begin{array}{c}\text { pmoles } \\
\text { mg protein } \cdot \min \end{array}\right)\end{array}$ & $\begin{array}{l}\text { Uptake of } 5-\mathrm{HT} \text { in } \\
\text { MCM due to } \mathrm{M}_{+}^{+} \\
\text {(per cent of total } \\
\text { uptake in fraction) }\end{array}$ \\
\hline $\begin{array}{l}\text { Bosmann and } \\
\text { Hemsworth [22] }\end{array}$ & 106 & 5.8 & 0.16 & 0.7 \\
\hline $\begin{array}{l}\text { Clark and } \\
\text { Nicklas [23] }\end{array}$ & 82 & 9.5 & 0.55 & 4.0 \\
\hline $\begin{array}{l}\text { Stahl et al. } \\
{[24]}\end{array}$ & 53 & 13.5 & 0.42 & 4.4 \\
\hline $\begin{array}{l}\text { Tjoie et al. } \\
{[25]}\end{array}$ & 87 & 10.0 & 0.97 & 7.5 \\
\hline $\begin{array}{l}\text { Gray and } \\
\text { Whittaker [21] }\end{array}$ & 47 & 17.6 & 0.26 & 3.5 \\
\hline $\begin{array}{l}\text { MCM fraction } \\
\text { (see Methods) }\end{array}$ & 18 & $<10$ & 1.29 & $<5$ \\
\hline
\end{tabular}

* Presented results are averages of two to four experiments

$\dagger$ Conditions for uptake were as outlined in Methods.

$\$$ Numbers in this column were obtained by multiplying the results in columns 2 and 3 and dividing by 1.29 , the value for 5-HT uptake in the MCM fraction.

5-HT uptake and NE uptake were potently inhibited by quinacrine.

Interaction of drugs with $\mathrm{Na}, \mathrm{K}$-ATPase. These studies were carried out with an enriched synaptosomal fraction, prepared according to Autilio et al. [20]. The mean specific activity of the enzyme in the preparation was $14.1 \pm 1.7 \mu$ moles $\mathrm{Pi} / \mathrm{mg}$ of protein $\cdot \mathrm{hr}$. The latter value represented 52 per cent of the total ATPase activity in the preparation. Previously
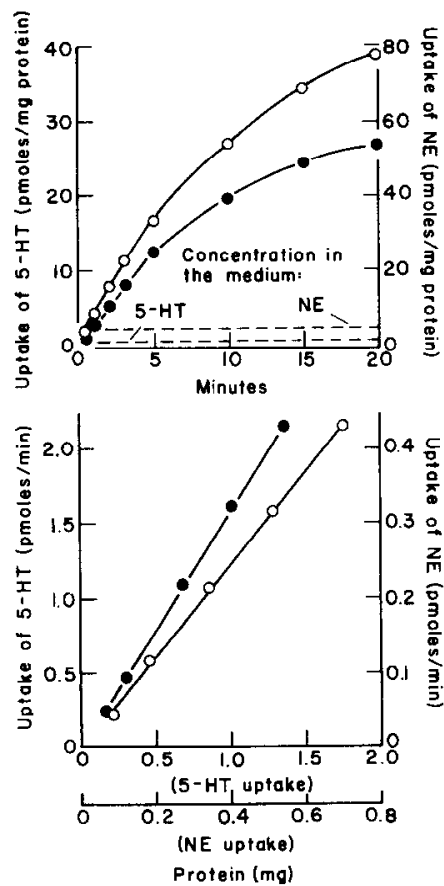

Fig. 2. Dependence of synaptosomal uptake of biogenic amines on time and protein. The uptake of 5-HT and of NE $(\mathrm{O}$ O) was determined as outlined in Materials and Methods. In experiments on protein dependence the uptake was terminated at times within the linear range. Shown are results of representative experiments. reported values for the activity of $\mathrm{Na}, \mathrm{K}$-ATPase in purified synaptosomal fractions from whole rat brain were 4.5 [42], 8.4 [35] and 12.8 [34], whereas in synaptosomes from cerebral cortex the activity was 6.4 [43], all expressed as $\mu$ moles $\mathrm{Pi} / \mathrm{mg}$ of protein $\mathrm{hr}$. At concentrations of $\mathrm{Na}^{+}$and $\mathrm{K}^{+}$approximating those normally prevailing in an extracellular environment, only three of the investigated drugs affected the $\mathrm{Na}$, K-ATPase (Table 4). Among them methadone, at a concentration of $0.5 \mathrm{mM}$, was the most potent, inhibiting the enzyme 56 per cent. Further investigation of the nature of methadone inhibition of synaptosomal ATPase revealed that the drug in inhibiting $\mathrm{Na}, \mathrm{K}-\mathrm{ATPa}$ e partially blocked the ouabain site of the enzyme (Table 5). This was indicated by the extent of the protective effect of methadone displayed in Expt. 5 relative to the results in Expt. 4. As shown in Expt. 3, considering in addition Expts. 5 and 4. methadone also inhibited the Mg-activated ATPase component.

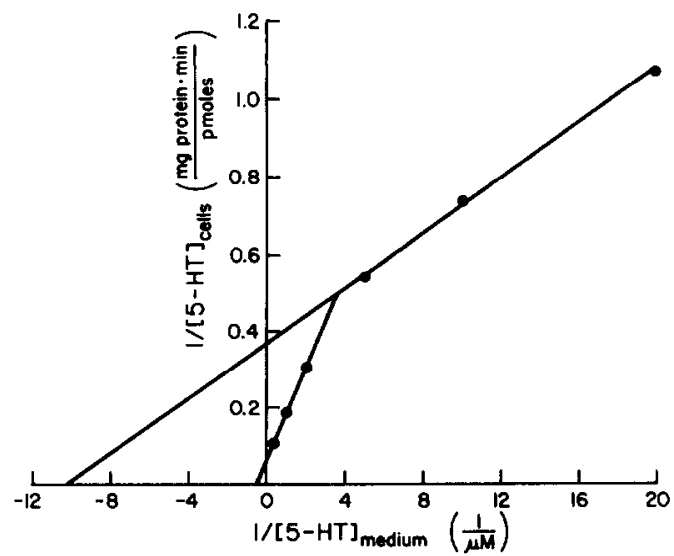

Fig. 3. Lineweaver-Burk plot of the uptake of 5-HT by the MCM fraction. Plotted are the reciprocal initial concentrations of 5-HT in the medium against the reciprocal rates of 5-HT uptake. The obtained values for $K_{m}$ and $V_{\max }$ are listed in Table 3. Presented are mean values of at least twenty experiments. 


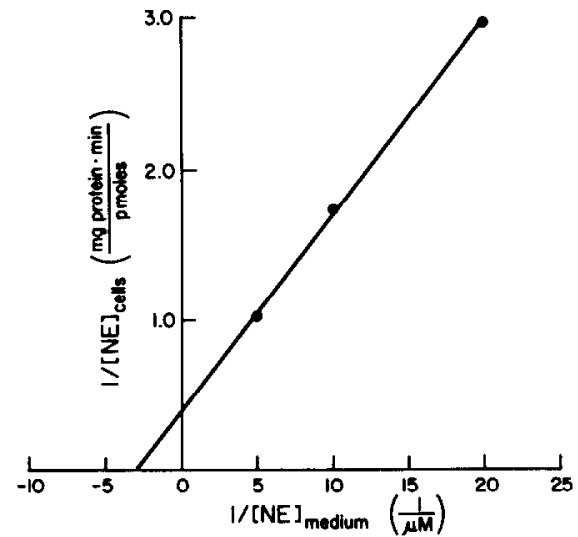

Fig. 4. Lineweaver-Burk plot of the uptake of NE by the MCM fraction. Plotted are the reciprocals of the initial concentrations of NE in the medium against the reciprocals of the rates of NE uptake. The obtained values of $K_{m}$ and $V_{\max }$ are listed in Table 3. Presented are mean values of at least twenty experiments.

Changing the ion concentration in the assay medium, i.e. decreasing the ratio $\mathrm{Na}^{+} / \mathrm{K}^{+}$, diminished the extent of inhibition of Na, K-ATPase by methadone (Table 5). As seen from Expts. 6-9, drug inhibition of the enzyme was 22 per cent at a ratio of $\mathrm{Na}^{+} / \mathrm{K}^{+}$equaling 1 as compared to 50 per cent if the latter was 20 . The inhibition of $\mathrm{Na}, \mathrm{K}$-ATPase by methadone was reversible. Washing of synaptosomes with $50 \mathrm{mM}$ imidazol $\cdot \mathrm{HCl}, \mathrm{pH} 7.0$, almost completely restored the enzyme activity, initially inhibited by $0.5 \mathrm{mM}$ methadone.

\section{DISCUSSION}

Since their discovery [21], synaptosomes have been increasingly used as conveniently available vesicular models to study biological phenomena in the synaptic region. Relating to transport processes, the synaptosomal uptake of biogenic amines [44] and amino acids $[45,46]$ has been focused upon. An essential requirement in investigating cellular transport processes is the assertion of an intact plasma membrane in the preparation under study. In comparing various measures of viability in isolated cells, we recently described the cellular $\mathrm{K}^{+}$content, or the ratio of cellular $\mathrm{K}^{+}$to cellular $\mathrm{Na}^{+}$, as most sensitive indicators of a nonleaking plasma membrane [37]. In the present study, synaptosomes further purified from the crude mitochondrial fraction displayed lower ratios

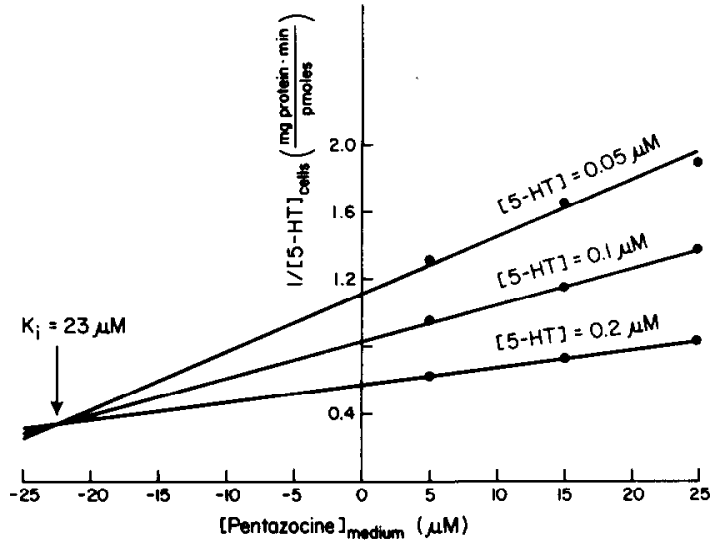

Fig. 5. Dixon plot for the determination of inhibition constants. Plotted are the reciprocal rates of biogenic amine uptake against the concentration of inhibitor in the medium. $K_{i}$ is determined from the point of intersection of three lines, each describing the uptake process at different concentrations of biogenic amine. Presented are the results of a typical experiment showing the inhibition of the high affinity 5-HT uptake by pentazocine.

of cellular $\mathrm{K}^{+} / \mathrm{Na}^{+}$as compared to a modified crude mitochondrial fraction. Compared to the latter preparation, the inferior transport-related viability of purified synaptosomes was also reflected in increased leakage of cellular LDH and did correlate with decreased uptake rates for biogenic amines, as well as with poor reproducibility of the data. This finding is supported by the results of a recent study showing decreased uptake of GABA and glutamate in purified synaptosomes if compared to incubation of the substrates with the $\mathrm{CM}$ fraction and subsequent isolation of the synaptosomes [47].

Crude mitochondrial fractions have been frequently used in studies focusing on uptake processes in synaptosomes (e.g. see Refs. 5, 7, 9 and 11). However, the use of such heterogeneous fractions requires the investigation of possible contribution to the observed phenomena of mitochondria, the major nonsynaptosomal vesicles present. In the present work, the contribution of mitochondria to synaptosomal uptake of biogenic amines was extensively investigated and determined to be less than 5 per cent of the total observed uptake. A recent electron-microscopic study on the morphology of CM and purified synaptosomes revealed that the latter organelles accounted for 38 per cent of all particles in either of the fractions [48] In remarkedly good agreement with our finding relat-

Table 2. Kinetic constants of 5-HT and NE uptake in MCM fraction*

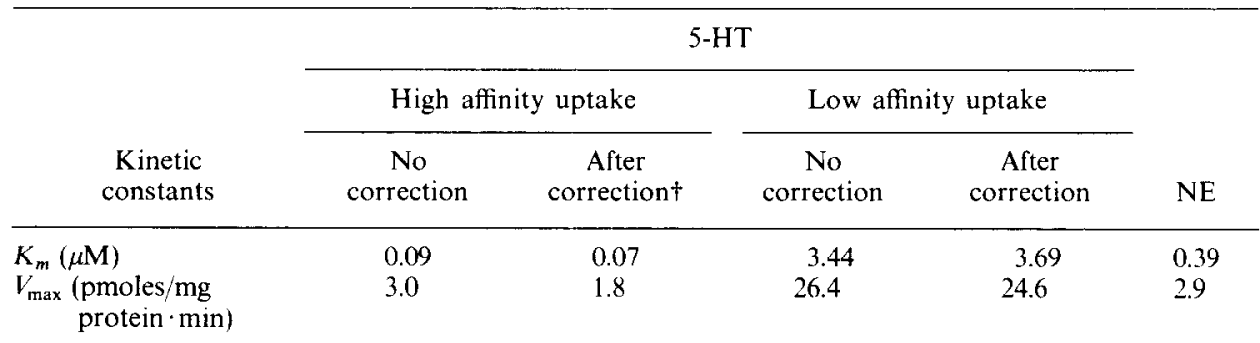

* Presented are mean values of at least twenty determinations using different preparations of synaptosomes. The standard deviation around the mean was less than \pm 15 per cent.

$\dagger$ Corrections were calculated according to Neal [41]. 
Table 3. Inhibition of the uptake of 5-HT and NE by CNS drugs*

\begin{tabular}{lcrr}
\hline & \multicolumn{2}{c}{ Inhibition $\begin{array}{c}\text { constants }\left(K_{i}\right) \\
(\mu \mathrm{M})\end{array}$} & NE \\
\cline { 2 - 3 } \multicolumn{1}{c}{ Drug } & \multicolumn{3}{c}{$5-\mathrm{HT}$} \\
& $\begin{array}{c}\text { High } \\
\text { affinity } \\
\text { uptake }\end{array}$ & $\begin{array}{c}\text { Low } \\
\text { affinity } \\
\text { uptake }\end{array}$ \\
\hline Levorphanol & 0.7 & 8 & 21 \\
Dextrorphan & 1.0 & 7 & \\
Desipramine & 4 & 10 & 5 \\
Quinacrine & 5 & 17 & 12 \\
Amphetamine & 9 & 9 & 37 \\
Pentazocine & 20 & 52 & 37 \\
Methadone & 28 & 30 & 32 \\
Codeine & 309 & $>1500$ & 1300 \\
Morphine & 615 & $>1500$ & 1350 \\
Naloxone & 807 & $>1500$ & 1120 \\
\hline
\end{tabular}

* Presented are averages of at least three determinations using different preparations of synaptosomes. The standard deviation of the mean was less than \pm 10 per cent.

ing to uptake (Table 1), the free mitochondria in the CM fraction represented 7 per cent of all the vesicles present. Possible artifacts in the uptake experiments due to variable activity of monoaminooxydase, resulting in deamination of the investigated compounds, were excluded by the demonstrated linearity of
Table 4. Effect of CNS drugs on synaptosomal ATPase*

\begin{tabular}{|c|c|c|}
\hline \multirow{2}{*}{$\begin{array}{c}\text { Drugs } \dagger \\
(0.5 \mathrm{mM})\end{array}$} & \multicolumn{2}{|c|}{ Activity as per cent of control } \\
\hline & Na, K-ATPase & Mg-ATPase \\
\hline Amphetamine & 89 & 100 \\
\hline Codeine & 100 & 100 \\
\hline Desipramine & 75 & 69 \\
\hline Levorphanol & 90 & 93 \\
\hline Methadone & 44 & 71 \\
\hline Morphine & 89 & 100 \\
\hline Naloxone & 96 & 100 \\
\hline Pentazocine & 92 & 85 \\
\hline Quinacrine & 76 & 90 \\
\hline
\end{tabular}

* In this part of the work, purified synaptosomes fraction C, according to Autilio it al. [20] were used. All values presented arc averages of three experiments. except for methadone, which was investigated in nine experiments. The standard deviation around the mean was \pm 7 per cent. + Synaptosomes were preincubated at 37 for $30 \mathrm{~min}$ with the particular drug. The assay of enzyme activity was started by the addition of ATP.

uptake with synaptosomal protein. Additional evidence against such interference was presented by the linear kinetics of the Dixon plots.

In order to establish a correlation with ongoing, transport-related studies in this laboratory, the synaptosomal preparations in the present work were iso-

Table 5. Characterization of methadone inhibition of ATPase*

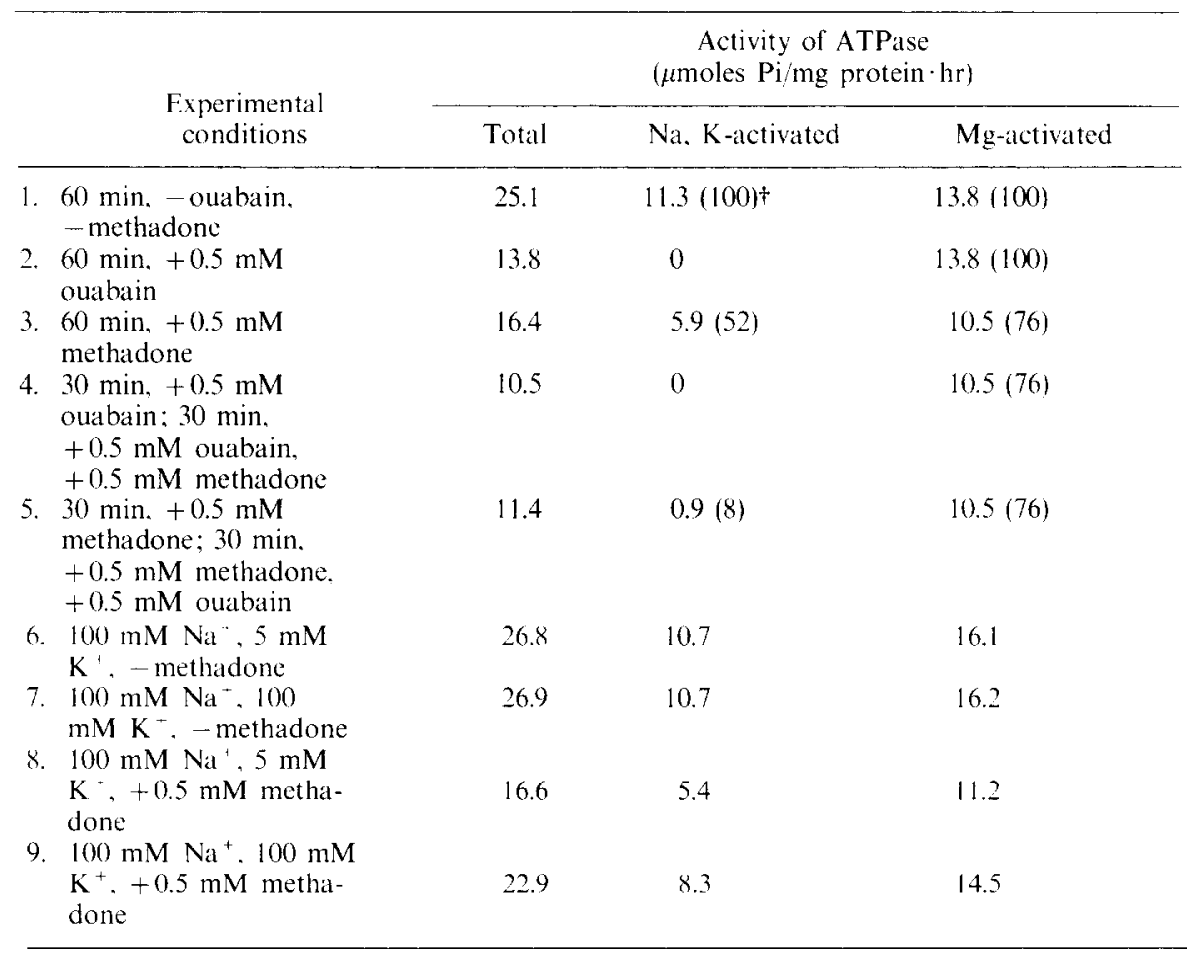

* After the preincubations at $37^{\circ}$ as indicated, the assay of ATPase was started with ATP and was carried out as described in Methods. Data from Expts. 1-5 indicate the site at which methadone interacts with $\mathrm{Na}, \mathrm{K}$-ATPase, whereas the results of Expts. 6-9 show the effect of ion concentration on drug inhibition of ATPase. The findings are interpreted in Results and Discussion. Presented are mean values of at least four experiments. The standard deviation around the mean was less than \pm 10 per cent.

$\dagger$ Figures in parentheses are per cent of controls. 
lated from cerebral cortex. Until recently cerebral cortex was assumed to be lacking in dopaminergic neurons $[49,50]$. However, newer evidence [51-53] contraindicates this concept describing the existence of DA nerve terminals in cortex, although limited to the limbic region [53]. In the present study, due to markedly low uptake rates and in agreement with the assumption of few dopaminergic terminals in cortex, a rcproducible accumulation of DA in cortical synaptosomes could not be established.

The values for kinetic constants determined in this study are within the range reported for neuronal uptake of 5-HT and NE $[1,54]$. However, in numerous hitherto presented studies there was little consistency in presenting the kinetic data, e.g. the extent of drug interaction was expressed as per cent inhibition relative to control. In addition, the biphasic uptake of biogenic amines was often graphically "resolved" by simply extending the corresponding lincs to obtain intercepts with the coordinates, resulting in two pairs of kinetic constants. In doing so the mutual interaction of the two processes was neglected. leading to quite arbitrary numerical values, particularly regarding the kinetic constants of the high affinity uptake process (Table 2).

Considering the viewpoint that the pharmacologic effect of various CNS drugs possibly represents the consequence of their interference in the synaptic uptake of biogenic amines, this study provides pertinent data using a wide selection of CNS drugs studicd under identical conditions. In evaluating the interactions, the different magnitude of the inhibition constants was focused upon, ranging from submicromolar to $\mathrm{mM}$ concentrations. Both desipramine and amphetamine were potent inhibitors of biogenic amine uptake. An exceptional effect was obtained with levorphanol, which inhibited the high affinity 5-HT uptake with a $K_{i}$ of $0.7 \mu \mathrm{M}$. The specificity of this effect is emphasized by the substantially lower potency of levorphanol in inhibiting the uptake of NE. The actions of levorphanol were not stereospecific, as shown by the similar $K_{i}$ value of dextrorphan. The high affinity binding of levorphanol in preparations from nervous tissue, reflecting the interaction with a narcotic receptor, has been shown to be stereospecific $[55,56]$. Relating to narcotic drugs, it is of interest to note the rather strong inhibitory potencies displayed by methadone and pentazocine as opposed to the weak effects of morphine, codeine and naloxone. The distinctly high $K_{i}$ values of the latter drugs present a strong argument against a biologic role of their interaction with the synaptosomal transport of biogenic amines in cerebral cortex.

In comparing the inhibitory pattern of the drugs in the present work with pertinent results of previous studies, one is hampered by the following differences: source of synaptosomes, number of drugs studied under identical conditions, and lack of a common method in expressing drug inhibition of biogenic amine uptake. Previous studies have particularly focused upon the effects of tricyclic antidepressants and amphetamine on the uptake of 5-HT $[3,5]$ and NE $[7,9]$. Amphetamine inhibited both the high and low affinity uptake of 5-HT with a $K_{i}$ of $7 \mu \mathrm{M}$ [5], which agrees with the finding in this study, showing similar $K_{i}$ values for this drug in inhibiting both uptake processes for 5-HT. Also in good agreement with results in Table 3 is the $\mathrm{IC}_{50}$ of $6 \mu \mathrm{M}$ reported for desipramine in inhibiting 5-HT uptake in crude synaptosomal preparations from whole rat brain [4]. On the other hand, our results disagree with the previously reported inhibition by methadone of synaptosomal 5-HT uptake [6]. Whereas in that study morphine exhibited a $K_{i}$ of $400 \mu \mathrm{M}$, a value approximating that shown in Table 3, methadone had a $K_{i}$ of $1 \mathrm{nM}$ as opposed to $28 \mu \mathrm{M}$ determined in the present work. Despite the differences in species (rabbit vs rat) and in brain regions (whole brain vs cerebral cortex), the discrepancy in the effects of morphine and methadone in the two studies is puzzling. Previously, the same laboratory reported morphine, methadone, thebaine and codeine to be potent inhibitors of synaptosomal NE uptake at concentrations between 0.2 and $2 \mathrm{mM}$ [8]. In addition to the markedly high concentrations of the drugs, morphine in that study was reported as more potent in inhibiting NE uptake than methadone. The study did not include $K_{i}$ values. These findings [8] again disagree with our observation that morphine, codeine and naloxone were markedly weak inhibitors of NE uptake as compared to the other CNS drugs investigated. On the other hand our results correlate well with the order of potency according to which narcotics, including morphine and methadone, inhibited NE uptake in a different study [10]. In that work, the $K_{i}$ values for morphine, codeine and naloxone were higher by 2 magnitudes than those for methadone and levorphanol. An additional study showed significant inhibition of synaptosomal NE uptake by 0.1 to $1 \mathrm{mM}$ concentrations of morphine [11]. The reported effects of tricyclic antidepressants on NE uptake [7,9] are in good agreement with the results shown in Table 3 , as exemplified by $K_{i}$ values of $8 \mu \mathrm{M}$ for amitriptyline [7] and $5 \mu \mathrm{M}$ for desipramine [4]

In evaluating drug interaction in this study, the potent effect of quinacrine in inhibiting both 5-HT and NE uptake is of interest. This compound proved to be a strong inhibitor of the transport of drugs in leukocytes [18,19]. the isolated retina [57] and in brain slices (Medzihradsky and Lin, unpublished observations). Quinacrine is apparently recognized as a substrate by uptake systems for basic amines, transport processes characterized by limited structural specificity and seemingly wide distribution in mammalian tissue [17-19].

The low affinity uptake of 5-HT has been assumed to be due to noradrenergic and/or dopaminergic neuronal uptake sites $[1,2,54]$. The inhibition pattern of the drugs investigated here presents strong evidence in support of this assumption: the $K_{i}$ values relating to the low affinity uptake of $5-\mathrm{HT}$ were similar to those obtained for the uptake of NE.

Inhibition of CNS drugs of the enzyme coupled to the transmembrane transport of $\mathrm{Na}^{+}$and $\mathrm{K}^{+}$ could reflect a possible mode of action of these compounds, due to induced changes in the concentration of monovalent ions in the synaptic cleft. However, at typical extracellular concentrations of $\mathrm{Na}^{+}$and $\mathrm{K}^{+}$ likely to reflect the ion content in the synaptic cleft [58], only methadone at submillimolar concentrations showed substantial and reversible inhibition of Na, K-ATPase. Although the effect was obtained with $0.5 \mathrm{mM}$ drug, this relatively high concentration is within the range of those applied in previous 
reports demonstrating partial inhibition of synaptosomal Na, K-ATPase by chlorpromazine and haloperidol [14]. and tricyclic anti-depressants [14,15]. In these studies, the effective concentration of the drugs was in the range of 0.1 to $1 \mathrm{mM}$. Tissue levels of basic amines, like methadone, can be expected to be considerably higher than their therapeutic concentration in plasma. As shown previously, among the drugs investigated here and at similar concentrations, desipramine and pentazocine inhibited by 40 and 15 per cent an enriched preparation of $\mathrm{Na}, \mathrm{K}$-ATPase from brain [59].

Changing the ion concentration in the direction which reflected synaptic $\mathrm{K}^{+}$release, i.e. at a decreased ratio of $\mathrm{Na}^{\prime} / \mathrm{K}^{1}$ in the assay, markedly diminished the extent of enzyme inhibition. This finding indicates limited effect of the drug on the active reuptake of $\mathrm{K}^{+}$, involving the $\mathrm{Na}, \mathrm{K}-\mathrm{ATPase}$, after synaptic discharge. The protective effect of $\mathrm{K}^{+}$, as well as results of the cross-inhibition experiments suggested partial involvement of the ouabain site in the interaction of methadone with $\mathrm{Na}, \mathrm{K}$-ATPase and also indicated inhibition by the drug of Mg-ATPase.

Acknowledgement--This study was supported in part by U.S. Public Health Service Grants 5P11 GM1559 and R01-DA-00254.

\section{REFERENCES}

1. L. L. Iversen, Biochem. Pharmac. 23, 1927 (1974).

2. L. L. Iversen, Br, med. Bull. 29, 130 (1973).

3. T. Segawa, T. Kuruma, K. Takatsuka and H. Takagi, J. Pharm. Pharmac. 20, 800 (1968).

4. M. H. Kannengiesser, P. Hunt and J. P. Raynaud, Biochem. Pharmac. 22, 73 (1973).

5. D. T. Wong, J. S. Hornig and R. W. Fuller, Biochem. Pharmac. 22, 311 (1973).

6. F. R. Ciofalo, J. Pharmac. exp. Ther. 189, 83 (1974).

7. A. S. Horn, J. T. Coyle and S. H. Snyder, Molec. Pharmac. 7, 66 (1971)

8. F. R. Ciofalo, Life Sci. 11 (Part I), 573 (1972).

9. J. E. Harris and R. J. Baldessarini, Neuropharmacology. 12, 669 (1973).

10. F. J. Carmichael and Y. Israel, J. Pharmac exp. Ther. 186, 253 (1973).

11. D. H. Clouet and N. Williams, J. Pharmac. exp. Ther 188, 419 (1974).

12. J. H. Dahl and L. E. Hokin, A. Ret. Biochem. 43, 327 (1974).

13. V. P. Whittaker, Prog. Biophys. molec. Biol. 15, 39 (1965).

14. P. G. Waser and E. Schaub, Adv. Cytopharmac. 1, 397 (1971).

15. C. G. Caratsch and P. G. Waser, Neuropharmacology 12, $563(1973)$.

16. F. Medzihradsky, M. J. Marks and E. A. Carr, Jr., Biochem. Pharmac. 21, 1625 (1972)

17. F. Medzihradsky, M. J. Marks and J. I. Metcalfe, Adv Biochem. Psychopharmac. 8, 537 (1973).

18. M. J. Marks and F. Medzihradsky, Biochem. Pharmac. 23, 2951 (1974).

19. M. J. Marks and F. Medzihradsky, Molec. Pharmac. 10, 837 (1974).

20. L. A. Autilio, S. H. Appel, P. Pettis and P. L. Gambetti, Biochemistry 7, 2615 (1968).

21. E. G. Gray and V. P. Whittaker, J. Anat. 96, 79 (1962).
22. H. B. Bosmann and B. A. Hemsworth, $J$, biol Chem 245, $363(1970)$

23. J. B. Clark and W. J. Nicklas, J. biol. Chem. 245, 4724 (1970).

24. W. L. Stahl, J, C. Smith, L. M. Napolitano and R E. Basford, J. Cell Biol. 19, 293 (1963).

25. S. Tjoic, C. P. Bianchi and N. Haugaard, Biochim biophys. Acta 216, 270 (1970).

26. G. L. Ellman, D. K. Courtney, V. Andres and R. M Featherstone, Biochem. Pharmac. 7, 88 (1961).

27. T. E. King, J. biol. Chem. 238, 4032 (1963).

28. F. Medzihradsky, M. J. Marks and J. I. Metcalfe, Biochem. Med. 10, 153 (1974)

29. D. W. Schulz, J. V. Passonneau and O. H. Lowry Analyt. Biochem. 19, 300 (1967)

30. F. Medzihradsky and H. L. Lin. Life Sci. 16, 1429 (1975).

31. O. H. Lowry, N. J. Rosebrough, A. L. Farr and R. J. Randall, J. biol Chem. 193, 265 (1951).

32. A. A. Andel-Latif, Biochim. biophys. Acta 121, 403 (1966).

33. E. De Robertis, A. P. De Iraldi, G. R. De I ores Arniaz and I. Solgarnicoff, J. Neurochem. 9, 23 (1962).

34. H. Tamir, M. M. Rapport and L. Roizin, J. Neturochem. 23, 943 (1974).

35. I. G. Morgan, L. S. Wolfe, P. Mandel and G. Gombos. Biochim. biophys. Acta 241, 737 (1971)

36. H. F. Bradford, J. Neurochem. 16, 675 (1969)

37. F. Medzihradsky and M. J. Marks, Biochem. Med. 13 , 164 (1975)

38. T. D. White and P. Keen, Biocheim. biophrs. Acta 196 285 (1970).

39. J. T. Archibald and T. D. White, Nature, Lond. 252 595 (1974)

40. M. P. Blaustein and J. M. Goldring, J. Physiol., Lond. 247, 589 (1975)

41. J. L. Neal, J. theor. Biol. 35. 113 (1972)

42. A. Daniel and L. Guth, Expl Neurol. 47, 181 (1975)

43. J. C. Gilbert, M. G. Wyllie and D. V. Davison, Nature.. Lond. 255, 237 (1975).

44. M. J. Kuhar, Life Sci. 13, 1623 (1973).

45. J. P. Bennett, Jr., W. J. Logan and S. H. Snyder, Science, N.Y. 178, 997 (1972).

46. N. A. Petersen and E. Raghupathy, J. Neurochem. 19 , $1423(1972)$

47. G. Levi and M. Raiteri, Brain Res. 57, 165 (1973).

48. F. Joó and J. Karnushina, J. Neurochem. 24, 839 (1975).

49. L. Olson and U. Ungerstedt, Acta physiol, scand. 67, $313(1966)$

50. U. Ungerstedt, Acta physiol. scand. 367, (suppl.). I (1971).

51. A. M. Thierry, L. Stinus, G. Blank and J. Glowinski. Brain Res. 50, 230 (1973).

52. A. M. Thierry, G. Blanc, A. Sobel, L. Stinus and J. Glowinski, Science, N.Y. 182, 499 (1973).

53. T. Hökfelt, A. Ljungdahl, K. Fuxe and O. Johansson. Science, N.Y 184, 177 (1974).

54. L. L. Iversen, in Drags and Transport Processes (Ed. B. A. Callingham), p. 275. Macmillan, London (1974).

55. A. Goldstein, L. I. Lowney and B. K. Pal, Proc. natn. Acad. Sci. U.S.A. 68, 1742 (1971)

56. W. A. Klee and M. Nirenberg, Proc. natn. Acal. Sci. U.S.A. 71, 3474 (1974).

57. D. J. Bednarczyk and F. Medzihradsky. Trans. Am Soc. Neurochem. 7. 226 (1976)

58. R. W. Colburn, F. K. Goodwin, D. L. Murphy, W E. Bunney and J. M. Davis, Biochem. Pharmac. 17, 957 (1968)

59. F. Medzihradsky and P. S. Nandhasri. Biochem. Pharmac, 21, 2103 (1972). 